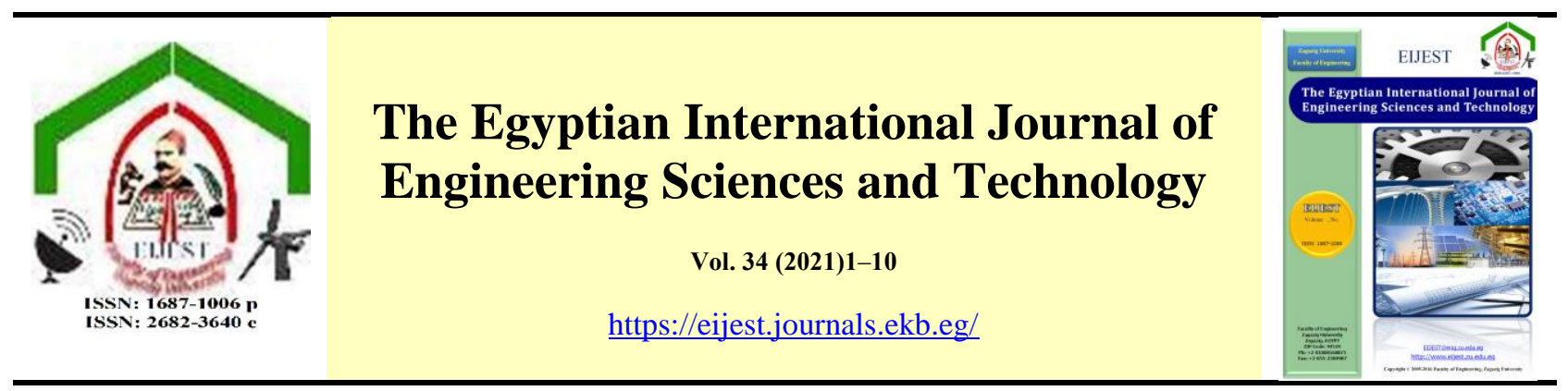

\title{
Effect of different screen widths on the submerged hydraulic jump characteristics
}

\begin{tabular}{|c|c|}
\hline \multicolumn{2}{|c|}{ Water and Water Structures Engineering Department, Faculty of Engineering, Zagazig University, zagazig, Egypt. } \\
\hline A R T I C L E I N F O & A B S T R A C T \\
\hline Keywords: & Hydraulic jump is used to dissipate excessive kinetic energy in natural water ways. \\
\hline $\begin{array}{l}\text { Submerged hydraulic jump, } \\
\text { Energy dissipation, } \\
\text { Sudden expanding stilling } \\
\text { basin. }\end{array}$ & $\begin{array}{l}\text { Screens fixed in the stilling basin to control the hydraulic jump location, depth and } \\
\text { length four decades ago. In this study, screens with a constant height and different } \\
\text { widths with the same screen relative area (Ar=0.285) were located behind the gate } \\
\text { at a distance of } 10 \mathrm{~cm} \text { and tested under wide variance conditions of submerged } \\
\text { hydraulic jump. Screens with different relative widths are tested to select the best } \\
\text { screen relative widths. The screen relative width of } 1.00 \text { had a maximum energy } \\
\text { loss and shortest length with a minimum tail water depth of the submerged } \\
\text { hydraulic jump. The theoretical deduced equation of the relative depth of the } \\
\text { submerged hydraulic jump had a higher asymmetric scatter with the experimental } \\
\text { results around the line of equality, however a good agreement was present when a } \\
\text { correction factor was used. }\end{array}$ \\
\hline
\end{tabular}

\section{Introduction}

Hydraulic jump is the natural phenomenon occurs when a flow transit from supercritical flow to subcritical flow. The main application of the hydraulic jump in open channels is magnifying the energy dissipation. Sluice gate is one of the commonly control structures used for controlling flows through channels for many decades. Controlling of the hydraulic jump can be attained by gradual expansions (France, 1981), sudden expansion (Hager, 1985), steps (Bejestan and Neisi, 2009), (Hager and Li, 1992) and (Negm et al., 2002; Negm et al., 2003), roughened bed (Bejestan and Neisi, 2009), blocks (Eloubaidy et al., 1999) .etc. Submerged sill is widely used to control the location of the hydraulic jump. Functions of lateral sills in a stilling basin depended on their locations. The sill can be existed under gate, fixed in the solid apron behind the gate or at the end of the basin. The sill under gate is used to reduce the gate height, consequently the gate weight also reduces, thus the initial and operation cost of gates are economic. (Abdel-Aal, 1990) studied the hydraulic jump characteristics for sill under vertical gate for free flow conditions. The presence of the sill reduced the relative energy loss with length and sequent depth more than that the case of no-sill. (Abdelhaleem, 2017) concluded the negative influence of sills under submerged radial gates and corrected the local scour phenomena occurred immediately downstream the stilling basin of some existing submerged jump with a radial gate sill in Egypt.(Bremen and Hager, 1994) determined the optimum sill height and its position downstream sudden expanding stilling basins. (Bukreev, 2001) studied the characteristics of the hydraulic jump over a rectangular broad sill. Conditions of transition from a free state to a submerged state of flow over the sill are considered when the second critical depth is reached over the downstream edge of the sill Moghadam et al (Fathi-Moghadam et al., 2011). 
studied experimentally forced hydraulic jumps in stilling basins for enforced cases due to tail water level or dam site arrangement. Significant effect of tall sill on dissipation of energy in shorter distance was confirmed. (Zare and Doering, 2012) compared between different configurations of baffles and sills with respect to the energy dissipation and the flow characteristics over stepped spillway. (Mohamed et al., 2015) studied the effect of different configurations and positions of sill over stilling basin on flow characteristics behind radial gate. It was found that the energy dissipation was increased by $30 \%$ compared to the no sill case. (Tajabadi et al., 2018) investigated the effect of the end sill angle on the hydrodynamic parameters of a stilling basin, it was found that the triangle end sill with angle of $60^{\circ}$ had the best performance by dissipating $62 \%$ of energy.

A perforated sill such as screens are commonly used in prismatic channels' stilling basins to maximize the energy dissipation and minimize the hydraulic jump length and its sequent depth. (Abbaspour et al., 2019) tested the hydraulic jump characteristics on a negative bed with porous screens. The study results showed that the adverse stilling basin with screens having the ability to dissipate energy greater than that corresponding stilling basin without screen. (Fathi-Moghadam et al., 2017) used a perforated sill to control the hydraulic jump. The results were presented in the form of mathematical models to estimate basin length the sill height, and sill position. The screen porosity was studied by (Daneshfaraz et al., 2019) (Abbaspour et al., 2019) and (Sadeghfam et al., 2015) to determine and select the best screen porosity that improve the characteristics of the hydraulic jump in the prismatic stilling basins. It was found that a screen porosity of $40 \%$ to $50 \%$ gave energy loss more than that of other porosities. (Bozkus et al., 2007) examined a vertical screen, while an inclined screen studied by (Balkiş, 2004), it was found that the vertical screen more effective from the energy dissipation point of view. (Bozkuş et al., 2006) and (Rajaratnam and Hurtig, 2000) investigated the energy dissipation by a triangular screen, while the square screen was studied by (Abbaspour et al., 2019) and circular screens and its effect on the hydraulic jump characteristics were reported by (Cakir, 2003). It was found that the square screens dissipate energy more than that of other shapes, this finding matched closely with (Mahmoud et al., 2013). (Hager, 1985), (Bremen and
Hager, 1993) and (Bremen and Hager, 1990) studied the free and submerged hydraulic jump in a sudden expanding stilling basin. It was found that the hydraulic jump parameters in a sudden expanding stilling basin were improved.

No available studies dealt with the characteristics of the submerged hydraulic jump supported by different screen widths in abrupt expanding stilling basins. This study aimed to investigate the effect of different screen widths on the hydraulic jump characteristics in a sudden expanding stilling basin with the same relative area.

\section{Experimental setup}

The experimental tests were performed in a recirculating flume of $0.30 \mathrm{~m}$ in width, $0.468 \mathrm{~m}$ in depth and $15.6 \mathrm{~m}$ in length with working section of $12.50 \mathrm{~m}$ in length as shown in photo (1). A centrifugal pump lifts the water from a sump tank to the flume inlet. The discharge of the flume is measured by a calibrated orifice meter. To adjust the required tail water depth, the tail gate can be gradually screwed until the considered depth. A point gauge was used to measure the water levels with an accuracy of $\pm 0.1 \mathrm{~mm}$.

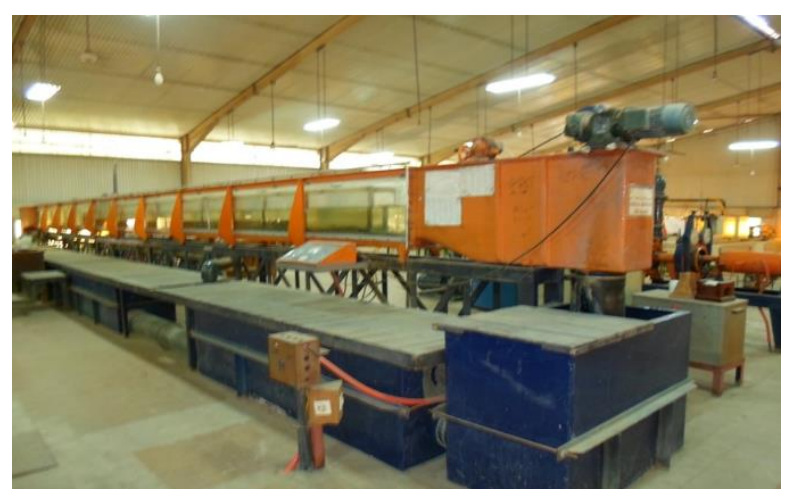

Photo (1) The mentioned flume

Screens with a $22 \mathrm{~cm}$ in width and $3 \mathrm{~cm}$ height has 24 holes with diameters $0.4,0.6,0.8,1.00$ and 1.2 $\mathrm{cm}$ with corresponding different relative holes area (Ar) 0.046, 0.103, 0.183, 0.285 and 0.411, respectively were used to investigate the effect of changing the screen passing area on the hydraulic jump characteristics. The case of no screen was considered a reference base to check the effect of screen with different relative area on the characteristics of hydraulic jump phenomenon.

The vertical screen model was built from clear 
Perspex, then placed at a distance of $10 \mathrm{~cm}$ from the gate in a sudden expanding stilling basin with a constant expansion ratio $(\mathrm{e}=1.35)$ downstream the vertical gate. For each experiment, the flow rate, water surface profile and the hydraulic jump length were measured. The inflow Froude number ranged from 2.25 to 8.45 with flow rates ranged from 5.99 to $15.85 \mathrm{l} / \mathrm{s}$ so as to cover the different submergence ratios $(S=3,4,4.5)$. About 153 runs were conducted, including 48 runs for a sluice gate with a submerged hydraulic jump without any modifications (i.e., case of no screen) for the comparison. Various models of screen in a stilling basin were tested to investigate the impact of the submergence ratio on the hydraulic jump characteristics.

\section{Energy Equation}

Figure (1) represents the schematic illustration of the supercritical flow impacting the screen and forming a hydraulic jump. The energy loss between sections 1-1 and 2-2 can be obtained by applying the energy principle with assuming the energy coefficients equal unity.

$$
\Delta \mathrm{E}=\mathrm{E}_{1}-\mathrm{E}_{2}=\left(\mathrm{y}_{3}+\frac{\mathrm{v}_{1}^{2}}{2 \mathrm{~g}}\right)-\left(\mathrm{y}_{4}+\frac{\mathrm{v}_{4}^{2}}{2 \mathrm{~g}}\right)
$$

\section{Where;}

$\mathrm{y}_{3}$ is the back-flow depth, $\mathrm{v}_{1}$ is the flow velocity at section 1-1 (i.e., the super critical flow velocity), and $\mathrm{y}_{4}$ and $\mathrm{v}_{4}$ are flow depth and velocity at section 2-2, respectively.

From a continuity equation:

Simplifying equation (5)

$$
\mathrm{v}_{4}=\frac{\mathrm{v}_{1} \mathrm{y}_{1} b}{\mathrm{y}_{4} B}
$$

Take $\frac{B}{b}=e, \frac{\mathrm{y}_{4}}{\mathrm{y}_{1}}=Y, \mathrm{v}_{4}=\frac{\mathrm{v}_{1}}{Y * e}$ and $\frac{\mathrm{y}_{3}}{\mathrm{y}_{1}}=S$

$$
\mathrm{E} 2=\mathrm{y} 4+\frac{\mathrm{v}_{1}^{2}}{2 \mathrm{Y}^{2} \mathrm{e}^{2} \mathrm{~g}}
$$

$$
E_{1}-E_{2}=y_{3}+\frac{v_{1}^{2}}{2 g}-y_{4}-\frac{v_{1}^{2}}{2 Y^{2} e^{2} g}
$$

$\frac{\Delta \mathrm{E}}{\mathrm{E} 1}=\frac{\frac{\mathrm{y}_{3}}{\mathrm{y}_{1}}+\frac{\mathrm{v}_{1}^{2}}{2 \mathrm{y}_{1} \mathrm{~g}}-\frac{\mathrm{y}_{4}}{\mathrm{y}_{1}}-\frac{\mathrm{v}_{1}^{2}}{2 \mathrm{Y}^{2} \mathrm{y}_{1} \mathrm{e}^{2} \mathrm{~g}}}{\frac{\mathrm{y}_{3}}{\mathrm{y}_{1}}+\frac{\mathrm{v}_{1}^{2}}{2 \mathrm{y}_{1} \mathrm{~g}}}$

$$
\begin{aligned}
& \frac{\Delta \mathrm{E}}{\mathrm{E} 1}= \\
& \frac{2 \mathrm{~S}+\mathrm{F}_{1}^{2}-2 \mathrm{Y}-\frac{\mathrm{F}_{1}^{2}}{\mathrm{Y}^{2} \mathrm{e}^{2}}}{2 \mathrm{~S}+\mathrm{F}_{1}^{2}}
\end{aligned}
$$

\section{The relative depth of the hydraulic jump}

To create a theoretical model for calculating the relative depth of the submerged hydraulic jump, the pressure-momentum relationship between sections 11 and 2-2 have been applied.

$$
\mathrm{P}_{1}+\mathrm{M}_{1}=\mathrm{P}_{2}+\mathrm{M}_{2}+2 \mathrm{P}_{\mathrm{s}}+\mathrm{Pc}_{\mathrm{net}}
$$

In which;

$\mathrm{P}_{1}=\frac{\gamma y_{1}^{2}}{2}(b)$ at $y_{1}$ (the hydrostatic pressure at the beginning of the hydraulic jump), $\mathrm{P}_{4}=$ $\frac{\gamma y_{4}^{2}}{2}(B)$ at $y_{4}$ (the hydrostatic pressure at the end of the hydraulic jump), $\mathrm{P}_{\mathrm{S}}=\frac{\gamma y_{S}^{2}}{2}\left(\frac{B-b}{2}\right)$ ( the hydrostatic pressure below one side of the contraction), $\quad \mathrm{P}_{\mathrm{c} 1}=\left(\frac{2 \gamma h_{1}-\gamma h_{s}}{2}\right)\left(\mathrm{B}_{\mathrm{s}} \mathrm{h}_{\mathrm{s}}-\frac{n \pi d^{2}}{4}\right) \quad$ (the hydrostatic pressure before the screen), $\mathrm{P}_{\mathrm{c} 2}=$ $\left(\frac{2 \gamma h_{2}-\gamma h_{s}}{2}\right)\left(\mathrm{B}_{\mathrm{s}} \mathrm{h}_{\mathrm{s}}-\frac{n \pi d^{2}}{4}\right)$ (the hydrostatic pressure after the screen) and $\mathrm{Pc}_{\text {net }}=\left(\mathrm{B}_{\mathrm{s}} \mathrm{h}_{\mathrm{s}}-\frac{n \pi d^{2}}{4}\right) \gamma\left(h_{1}-\right.$ $h_{2}$ ) (the net pressure applied on screen)

Where;

$h_{s}$ is the screen height, $B_{s}$ is the screen width, $d$ is the diameter of the screen holes, $\mathrm{y}_{\mathrm{s}}$ is the water depth just after the abutments contraction, $A_{s}$ is the total area of $\operatorname{screen}\left(A_{s}=B_{s} h_{s}\right), A_{o}$ is the area of holes $\left(A_{o}=0.25 n \pi D^{2}\right)$ and $n$ is the number of holes.

By substituting in the momentum equation no. (7)

$$
\begin{aligned}
\frac{\gamma y_{3}^{2}}{2}(b)+\rho Q v_{1} & =\frac{\gamma y_{4}^{2}}{2}(B)+\rho Q V_{4}+2 \frac{\gamma y_{s}^{2}}{2}\left(\frac{B-b}{2}\right) \\
& \left.+\left(B_{s} h_{s}-\frac{n \pi d^{2}}{4}\right) \gamma\left(h_{1}-h_{2}\right)\right)
\end{aligned}
$$

Rearrangement and simplify equation (8)

$$
\begin{aligned}
2 \mathrm{~F}_{1}^{2}\left(1-\frac{1}{\mathrm{eY}}\right)= & \mathrm{Y}^{2} * \mathrm{e}+\mathrm{y}_{\mathrm{s}}^{2}(\mathrm{e}-1) \\
& +\left(\mathrm{A}_{\mathrm{s}}-\mathrm{A}_{0}\right) \frac{2 \mathrm{e} \Delta \mathrm{H}}{\mathrm{By}_{1}^{2}}-\mathrm{S}^{2}
\end{aligned}
$$


$=\frac{\left.\mathrm{Y}^{2} * \mathrm{e}+\mathrm{y}_{\mathrm{s}}^{2}(\mathrm{e}-1)+\left(\mathrm{A}_{\mathrm{s}}-\mathrm{A}_{0}\right)\right) \frac{2 \mathrm{e} \Delta \mathrm{H}}{\mathrm{By}_{1}^{2}}-\mathrm{S}^{2}}{2\left(1-\frac{1}{\mathrm{eY}}\right)}$

$A_{\text {net }}=$
area

$A_{\text {net }}$ is the net screen area

$\mathrm{F}_{1}^{2}$

$=\frac{\mathrm{Y}^{2} * \mathrm{e}+\mathrm{y}_{\mathrm{s}}^{2}(\mathrm{e}-1)+\left(\mathrm{A}_{\mathrm{net}}\right) \frac{2 \mathrm{e} \Delta \mathrm{H}}{\mathrm{By}_{1}^{2}}-\mathrm{S}^{2}}{2\left(1-\frac{1}{\mathrm{eY}}\right)}$

The equation no. (11) is the general equation of the submerged hydraulic jump occurred in a stilling basin provided by screen.

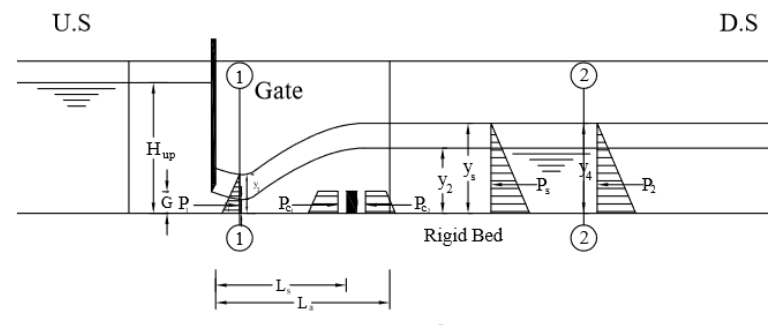

SEC. ELEVATION

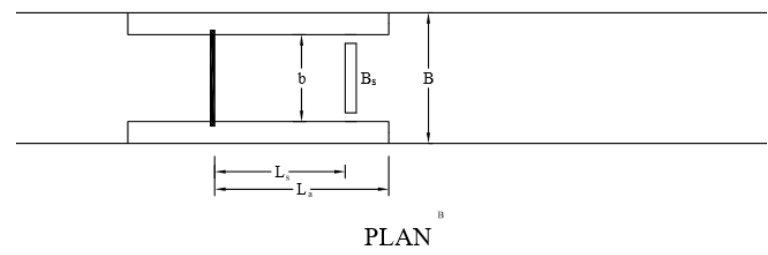

Figure (1) schematic illustration of the submerged hydraulic jump induced by screen

\section{Dimensional analysis}

Dimensional analysis was used to correlate the different variables affected on dissipated energy through screen downstream vertical gate as following;

$$
\begin{aligned}
& f\left(B, b, B_{s}, L_{s}, G, L_{a}, h_{s}, d, n, H_{u p}, y_{1}, y_{3}, y_{4}, L_{j}, v_{1},\right. \\
& \left.g, E_{1}, E_{2}, \Delta E, \rho, \mu\right) \\
& =0.0
\end{aligned}
$$

Where, $\mathrm{B}$ is a channel width, $\mathrm{b}$ is a contracted width, $B$ s is a screen width, $G$ is a gate opening, $L_{a}$ is a length of abutment downstream the gate, $h_{s}$ is a screen height, $\mathrm{d}$ is a screen holes diameter, $\mathrm{n}$ is a number of holes, $\mathrm{H}_{\mathrm{up}}$ is the upstream water depth, $\mathrm{y}_{1}$ is the initial water depth, $\mathrm{y}_{3}$ is the back flow depth, $\mathrm{y}_{4}$ is the tail water depth, $\mathrm{L}_{\mathrm{j}}$ is the jump length, $v_{1}$ is velocity at section1-1, $\mathrm{g}$ is the gravitational acceleration, $E_{1}$ is the total energy at $y_{1}, E_{2}$ is the total energy at $y_{4}, \Delta E$ is the energy loss through the hydraulic jump, $\rho$ is the density of water and $\mu$ is the dynamic viscosity of water.

By merging the resultant dimensionless parameters;

$f\left(\frac{B}{y_{1}}, \frac{b}{y_{1}}, \frac{B_{s}}{y_{1}}, \frac{L_{s}}{y_{1}}, \frac{G}{y_{1}}, \frac{L_{a}}{y_{1}}, \frac{h_{s}}{y_{1}}, \frac{d}{y_{1}}, n, \frac{H_{u p}}{y_{1}}, \frac{y_{3}}{y_{1}}, \frac{y_{4}}{y_{1}}, \frac{L_{j}}{y_{1}}, \frac{1}{F^{2}}, E_{1}\right.$

$\left./ y_{1}, E_{2} / y_{1}, \Delta E / y_{1}, 1 / R_{n}\right)=0.0$

$R_{n}$ has a very small effect in the open channel and it can be neglected.

The screen height, screen position, screen relative area and the expansion ratio were constants through this study. By simplify the previous equation then;

$$
\frac{l_{j}}{y_{1}}, \frac{y_{4}}{y_{1}}, \frac{\Delta E}{E_{1}}=f\left(F_{1}, \frac{B_{s}}{b}, S\right)
$$

Where $F_{1}$ is the initial Froude number, $\mathrm{S}=\mathrm{y}_{3} / \mathrm{y}_{1}$ is the submergence ratio $\mathrm{B}_{\mathrm{s}} / \mathrm{b}$ is the relative screen width

\section{Results and discussions}

The effect of the relative screen width $\left(\mathrm{B}_{\mathrm{s}} / \mathrm{b}\right)$ on the hydraulic jump characteristics were monitored. To determine the best relative width of screen, the screen was fixed in the best location with a best relative area. The best screen location was found at a relative distance of 0.25 , and the best relative screen area was 0.285 . It is worth to note that the relative width of the screen changes from 0.43 to 1.00 .

\subsection{The relative energy loss of the hydraulic jump.}

Figure (1) to Figure (3) describe the relationship between the relative energy loss $\left(\Delta \mathrm{E} / \mathrm{E}_{1}\right)$ versus the initial Froude number $\left(\mathbf{F}_{1}\right)$ for different submergence ratios 3.0, 4.0 and 4.5 for different relative screen widths $0.43,0.50,0.70,0.92$ and 1.00 . It can be clearly seen that the increasing of Froude number accompanied by an increasing in the relative energy loss. At a certain Froude number, the relative energy loss for the same submergence ratio degree increases as the screen relative width increases. 


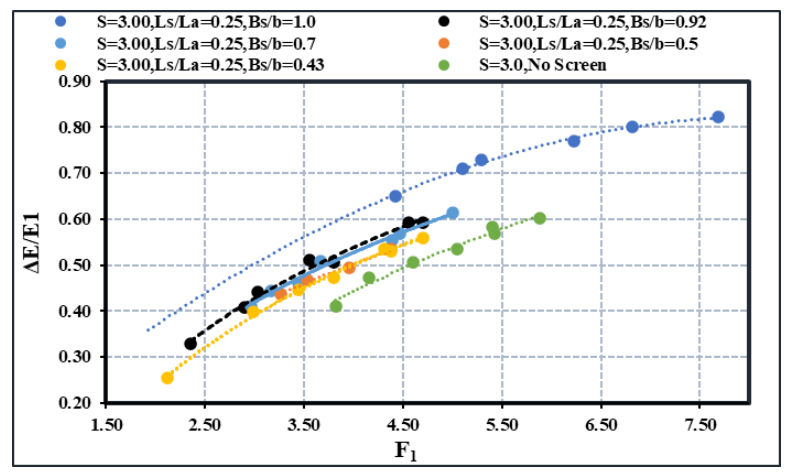

Figure ( 1) Relations between $F_{1}$ and $\Delta E / E_{1}$ for $S=3.00$ for different $B_{s} / b$ ratios .

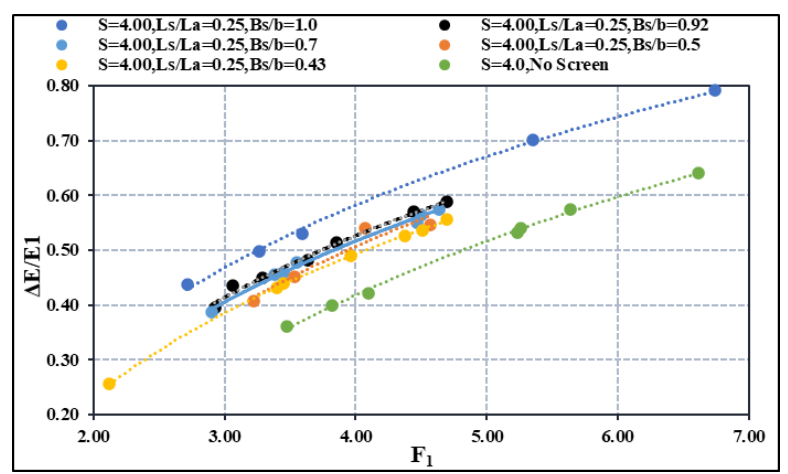

Figure ( 2)Relations between $\mathbf{F}_{\mathbf{1}}$ and $\Delta \mathrm{E} / \mathrm{E}_{1}$ for $\mathbf{S}$ $=3.00$ for different $\mathrm{B}_{\mathrm{s}} / \mathrm{b}$ ratios.

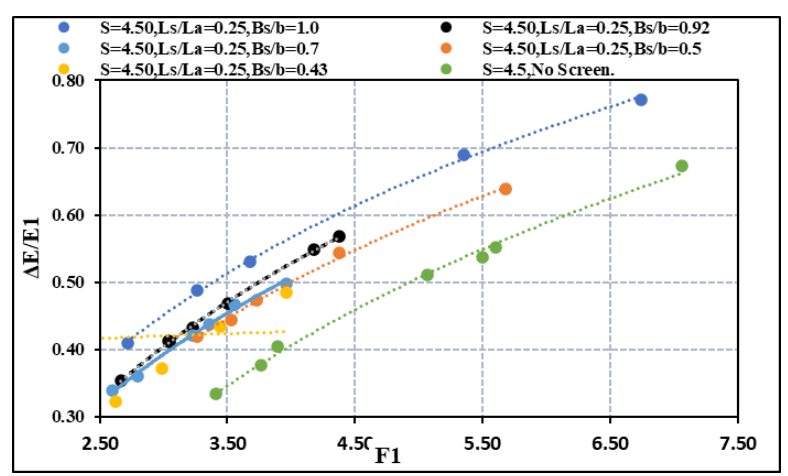

Figure ( 3) Relations between $\mathbf{F}_{1}$ and $\Delta \mathrm{E} / \mathrm{E}_{1}$ for $\mathbf{S}$ $=4.50$ for different $\mathrm{Bs} / \mathrm{b}$.

Error! Reference source not found.) showed the maximum increasing percentage of the relative energy loss occurred at the relative screen width of 1.00 for all submergence ratios. The increasing percentage of the relative energy loss had a direct proportional with the submergence ratio at the same relative width. This means that the increasing percentage of the relative energy loss increased as the submergence ratios increased. In other words, the screen is more effective in the case of higher submergence ratios values. The effect of screen at the relative width $\geq 0.92$ on the increasing percentage of the relative energy loss was identical, regardless of the submergence ratio.

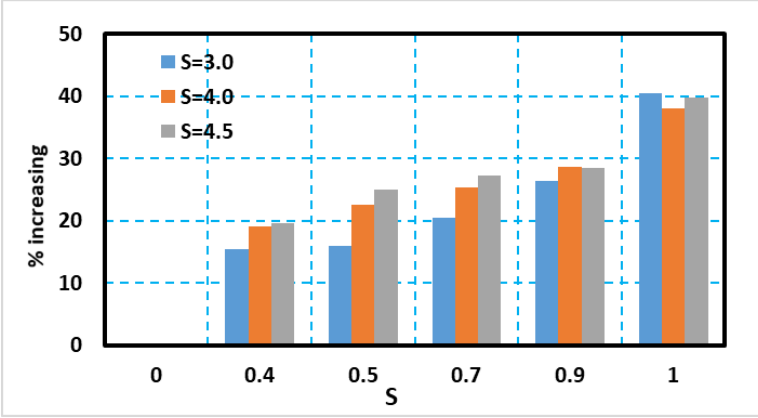

Figure (4) ncreasing percentage of relative energy loss for $\mathbf{S}=3.0,4.0$ and 4.5 and $\mathrm{B}_{\mathrm{s}} / \mathrm{b}=0.43,0.5,0.7$, 0.92 and 1.00 at $\mathbf{F}_{1}=4.00$

\subsection{The relative depth of the hydraulic jump.}

Figure (5) to Figure (7) show the relationship between the relative depth of the hydraulic jump and the initial Froude number for different submergence ratios $\mathbf{S}=3.0,4.0$ and 4.5 for different relative screen widths $0.43,0.5,0.7,0.92$ and 1.00 . From these figures, it is clear that the behavior of the relative depth of the hydraulic jump has the same trend with the initial Froude number as mentioned previously. In other words, any increasing or decreasing in Froude number leads to a corresponding increasing or decreasing in the relative hydraulic jump depth. Besides, the relative depth of the hydraulic jump increases as the submergence ratio increases at a specific Froude number. Moreover, all the tested relative screen widths give a minimum value of the relative depth of the hydraulic jump with respect to the case of no screen.

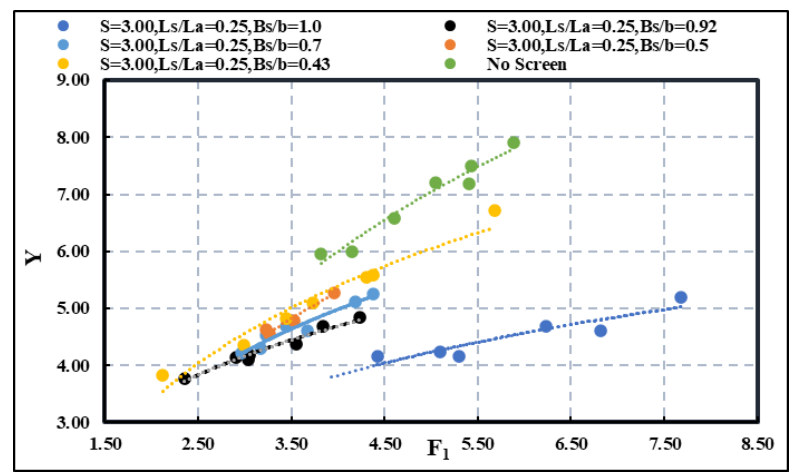

Figure ( 5) Relations between $\mathbf{F}_{1}$ and $\mathrm{Y}$ for $\mathbf{S}=3.00$ for different $\mathrm{B}_{\mathrm{s}} / \mathrm{b}$ ratios. 


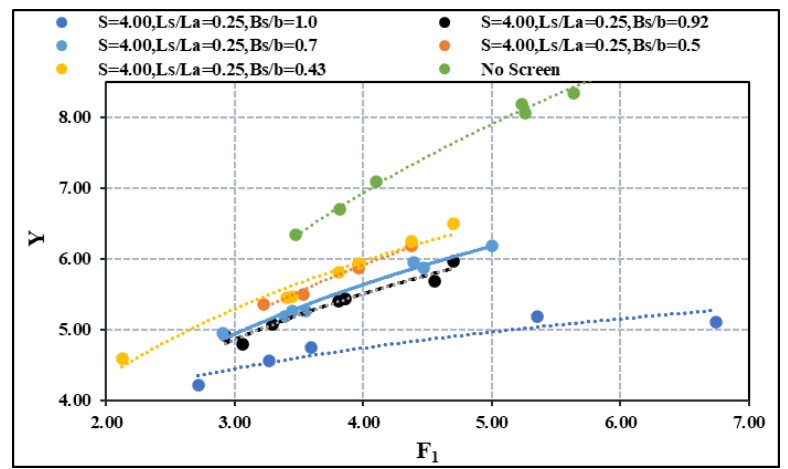

Figure ( 6) Relations between $\mathbf{F}_{\mathbf{1}}$ and $\mathrm{Y}$ for $\mathbf{S}=4.00$ for different $\mathrm{B}_{\mathrm{s}} / \mathrm{b}$ ratios.

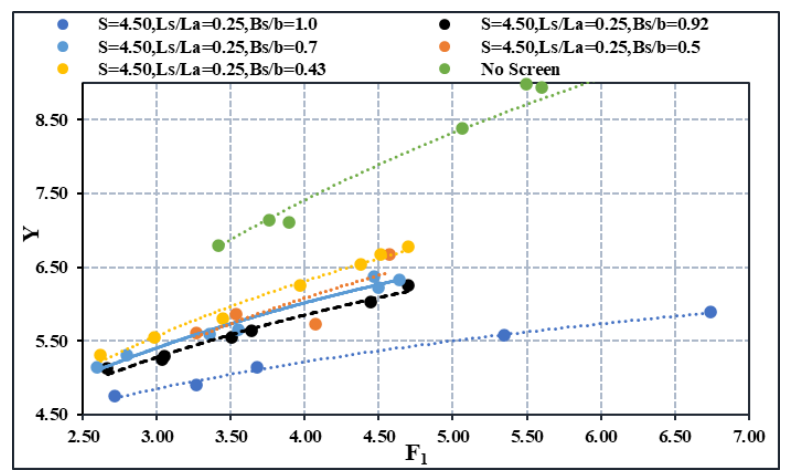

Figure ( 7) Relations between $\mathbf{F}_{\mathbf{1}}$ and $\mathrm{Y}$ for $\mathbf{S}=4.50$ for different $\mathrm{B}_{\mathrm{s}} / \mathrm{b}$ ratios

Figure ( 8)show the decreasing percentage of the relative hydraulic jump depth for the submergence ratios 3.00, 4.00 and 4.50 and $\mathbf{F}_{1}=4.00$, for the Bs/b ranges from 0.43 to 1.0 . It can be clearly seen from this figure that with increasing the relative screen width the decreasing percentage of the relative hydraulic jump depth increases. The decreasing percentage of the relative hydraulic jump depth has approximately the same values at 0.92 relative screen width. The decreasing percentage of the relative hydraulic jump depth is directly proportional to the submergence ratio when the relative screen width $<0.92$. However, it has an inversed proportional to the submergence ratio when the relative screen width $>0.92$ and the values of the decreasing percentage are almost identical for the submergence ratio 3.0 and 4.0.

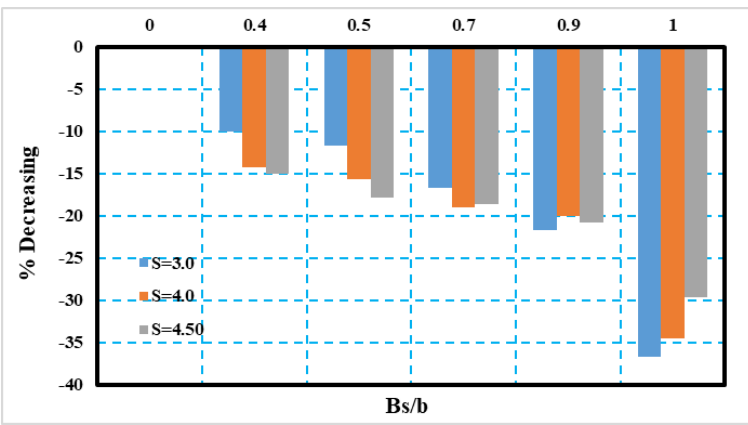

Figure ( 8 ) The decreasing percentage of the relative depth of jump for $\mathbf{S}=3.0,4.0$ and 4.5 and $\mathrm{B}_{\mathrm{s}} / \mathrm{b}=0.43$, $0.5,0.7,0.92$ and 1.00 at $\mathbf{F}_{1}=4.00$

\subsection{The relative length of the hydraulic jump}

Figure ( 9) to Error! Reference source not found.) show the relationship between the relative length of the hydraulic jump and initial Froude number for different relative widths $\left(B_{s} / b\right) 0.43,0.5$, $0.7,0.92$ and 1.00. For all different submergence ratios 3.0, 4.0 and 4.5, as Froude number increases the relative length of the hydraulic jump increases also. For the same Froude number, the relative length of the hydraulic jump decreases as the relative width of the screen increases.

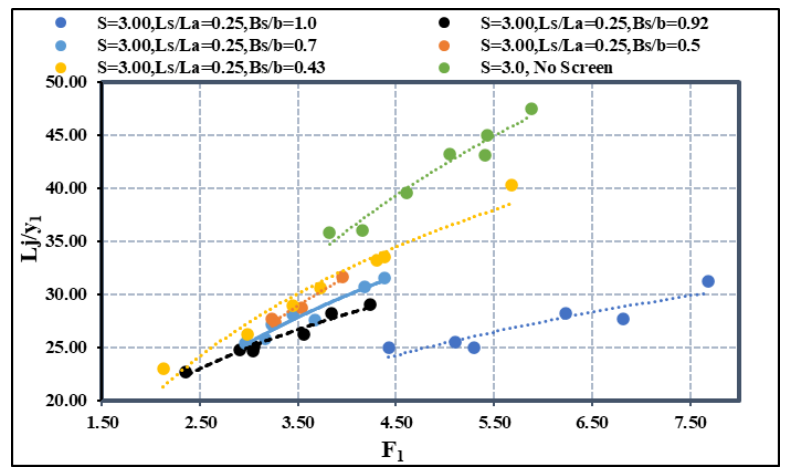

Figure ( 9) Relations between $\mathbf{F}_{1}$ and $\mathrm{L}_{\mathrm{j}} / \mathrm{y}_{1}$ for $\mathbf{S}=$ 3.00 for different $\mathrm{B}_{\mathrm{s}} / \mathrm{B}$ ratios.

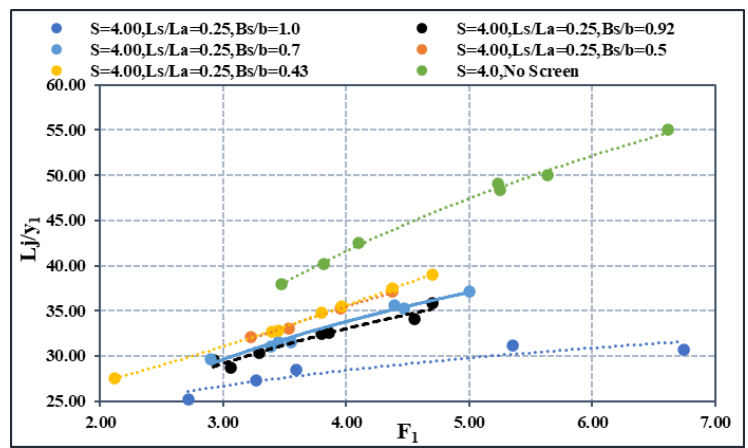

Figure ( 10) Relations between $\mathrm{F}_{1}$ and $\mathrm{L}_{\mathrm{j}} / \mathrm{y}_{1}$ for $\mathrm{S}=4.00$ for different $\mathrm{B}_{\mathrm{s}} / \mathrm{b}$ ratios. 


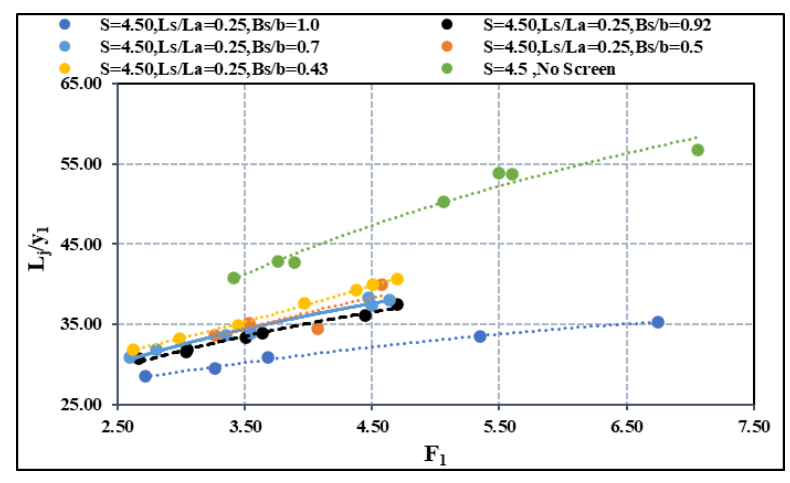

Figure (12) Relations between $\mathrm{F}_{1}$ and $\mathrm{L}_{\mathrm{j}} / \mathrm{y}_{1}$ for $\mathrm{S}=$ 4.50 for different $B_{s} / b$ ratios.

Figure (13) describes the decreasing percentage in the relative length of the hydraulic jump for the submergence ratios 3.00, 4.00 and 4.50 at Froude number 4.0 for the relative screen widths $0.43,0.5$, 0.7, 0.92 and 1.00. Again, the maximum decreasing percentage of the relative hydraulic jump length happens at the relative width equals 1.00 for all submergence ratios. At the relative width equals 0.92 the decreasing percentage in the relative hydraulic jump length was almost identical for all submergence ratios 3.0, 4.0 and 4.5. in the case of submergence ratio to 0.92 , the decreasing percentage in the relative hydraulic jump length for the submergence ratio 3.0 was the higher value. However, in the case of the submergence ratios 4.0 and 4.5 , the decreasing percentage was identical and their values were higher than those in the submergence ratio 3.0.

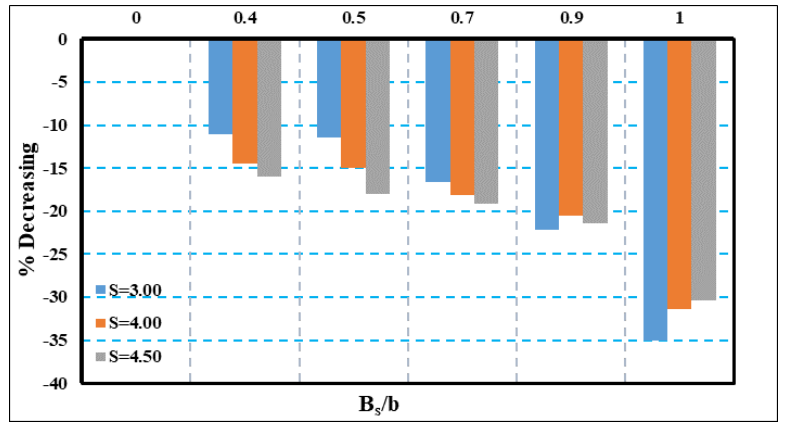

Figure (11) Decreasing percentage of relative length of jump $\mathbf{S}=3.0,4.0$ and 4.5 and $B_{s} / b=0.43,0.5,0.7$,

0.92 and 1.00 at $\mathbf{F}_{1}=4.00$

\subsection{The water surface profile}

The water surface profiles in the case of changing the screen widths are shown in Figure (14) to Figure ( 16) for the submergence ratios 3.00, 4.00 and 4.50 and the relative widths of screen $\mathrm{Bs} / \mathrm{b} 1.0,0.92,0.7$ and 0.43 . It can be clearly seen that the less of the relative screen width is, the higher water surface profile is front and back of the screen as shown in Figure (15)It was noticed that with increasing the $\mathrm{Bs} / \mathrm{b}$ ratio, the lower water surface profile decreases as indicated in Figure (16). It can be concluded that the best results occur in the case of presence the screen with a whole width of the contracted part of the waterway. The total discharge is divided into three parts, the first one passes through the screen, the second part flows over the screen and the third part flows around the screen. As the relative width of the screen increases, the flow through the screen increases, thus the around discharge decreases. This leads to extra crossing between the over and through discharges, therefore the turbulence increases and more energy dissipation causes a reduction in water surface profile. It is clear from these figures that the tail water depth ( $\mathrm{y} 4$ ) for the $\mathrm{Bs} / \mathrm{b}=1.00$ has minimum values compared to all other relative screen widths. Moreover, the impact of water on the screen plays an important rule from the energy dissipation point of view. As the width of the screen increases the impact increases also. This causes extra energy dissipation and more reduction in tail water depth. Furthermore, the net difference of water depths between the front and back of the screen increases as the relative width of the screen increases. So, the back pressure on the screen increases, which reduces the tail water depth

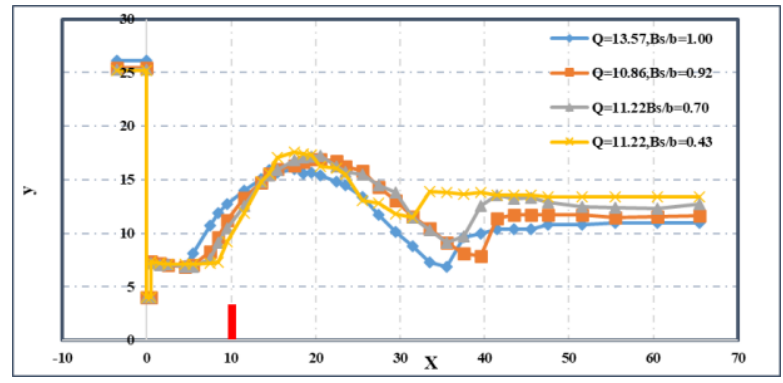

Figure (14) Water surface profile of submerged jump for constant $S=3.0$ and constant $G=3.5$.

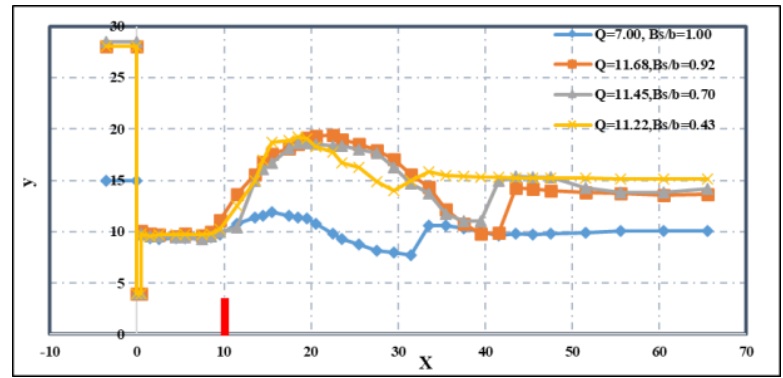

Figure (12) Water surface profile of submerged jump for constant $\mathbf{S}=4.0$ and constant $\mathbf{G}=4.0$. 


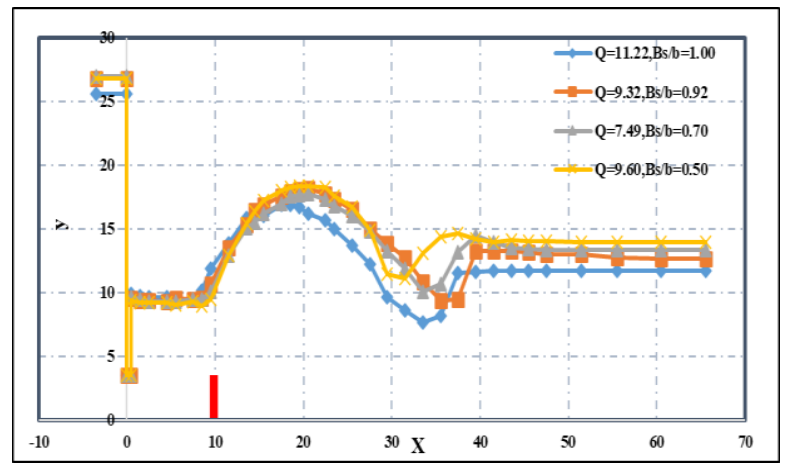

Figure (16) Water surface profile of submerged jump for constant $S=4.0$ and constant $\mathrm{G}=4.0$

\section{Verification}

The relationship between the theoretical results of the relative hydraulic jump depth calculated from equation (11) and the experimental results was shown in

Figure ( 13). From this figure, it was found a higher asymmetric scatter of results around the line of equality. Thus, a correction factor is required to correct the theoretical Froude number as presented in equations (15 and 16).

$$
\mathrm{Fc}_{\mathrm{th}}=\mathrm{F}_{\mathrm{th}}+\mathrm{CF}
$$

Where; $\mathrm{CF}$ is the correction factor and $F c_{t h}$ is the corrected theoretical Froude number

$$
\mathrm{CF}=0.5 \mathrm{Y}-0.8 \mathrm{~S}+2.8\left(\frac{B_{s}}{\mathrm{~b}}\right)-2.0
$$

The corrected theoretical and experimental Froude numbers are shown in

Figure (14). From this figure a good agreement between the results of equation (15) and the experimental results. To verify the theoretical relative energy loss from equation (6), substituting the corrected theoretical Froude number calculated from equation (15) and other reminder variables from the experimental data.

Figure ( 15 ) indicates the theoretical relative energy loss derived from equation (6) and the experimental results, a well agreement can be clearly seen. Consequently, the derived equations can be used for designing stilling basins supported with screens in practical applications

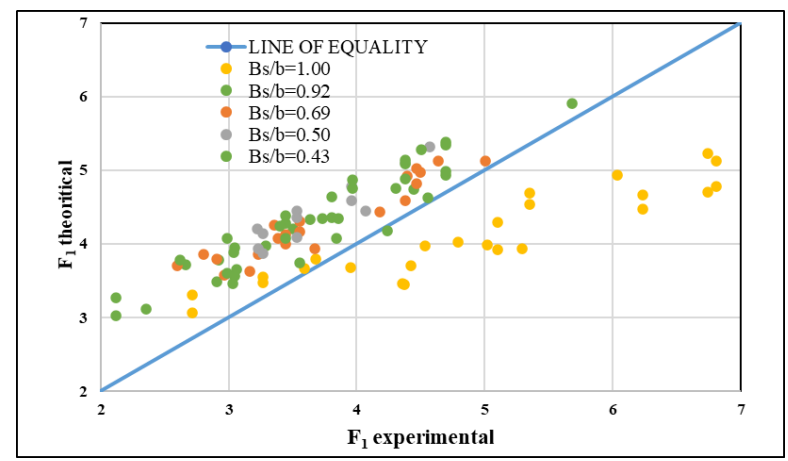

Figure ( 13) The relationship between theoretical $\mathbf{F}_{\mathbf{1}}$ of equation (11) and experimental Froude number

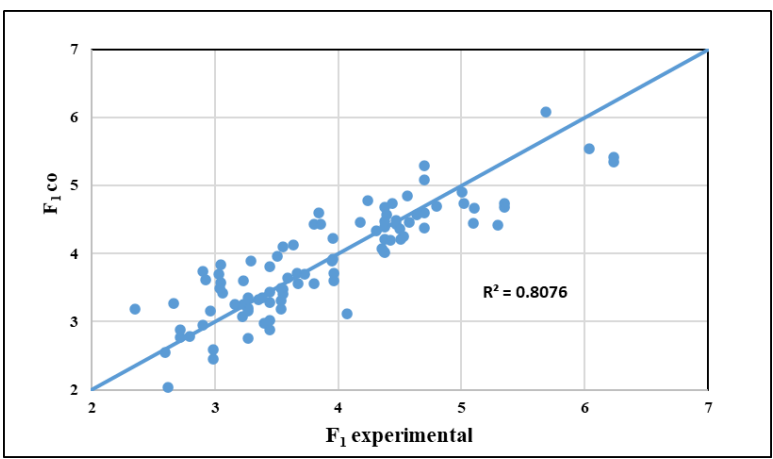

Figure ( 14) The relationship between corrected theoretical $\mathbf{F}_{1}$ of equation (11) and experimental Froude number

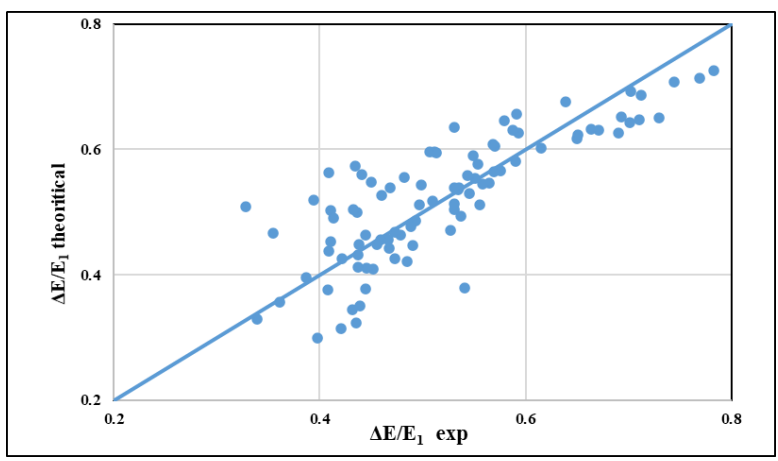

Figure (15) The relationship between theoretical $\Delta \mathbf{E} / \mathbf{E}_{\mathbf{1}}$ of equation (6) and experimental $\Delta \mathbf{E} / \mathbf{E}_{\mathbf{1}}$.

\section{Conclusion}

Experimental and theoretical studies related to the sudden expanding stilling basin supported by screens were done to show the effect of the presence of screen on the characteristics of the submerged hydraulic jump. The present study introduces the following results; 
1. The presence of screen with any relative widths improved the characteristics of the submerged hydraulic jump.

2. The best screen relative width that increased the relative energy loss and decreased the relative depth and length of the submerged hydraulic jump was about 1.00 .

3. The derived theoretical equation of the relative depth of the hydraulic jump had a higher asymmetric scatter with the experimental results around the line of equality, however an acceptable agreement was present when a correction factor was used.

4. The deduced theoretical equation of the relative energy loss had acceptable agreement with the experimental results.

\section{Notation}

$A_{s}$ The total screen area $\left(\mathrm{L}^{2}\right)$

$A_{o}$ Area of holes $\left(\mathrm{L}^{2}\right)$

$A_{r}$ relative area of the screen

$b$ Contracted width

$B$ Channel width (L)

$B_{s}$ Screen width (L)

$B_{s} b$ relative width of the screen

$d$ Diameter of holes of screen (L)

$\Delta E$ Energy loss through jump (L)

$E_{1}$ Total energy at $\mathrm{y}_{1 .}(\mathrm{L})$

$E_{2}$ Total energy at $\mathrm{y}_{4}(\mathrm{~L})$

$e$ Expansion ratio (-)

$F_{l}$ Inflow Froude number (-)

$g$ Gravitational acceleration $\left(\mathrm{LT}^{-2}\right)$

$G$ Gate opening (L)

$H_{u p}$ Upstream water depth (L)

$h_{s}$ Screen height (L)

$\Delta H$ Difference between water depths U.S and D.S the screen

$L_{a}$ Length of abutment downstream the gate

$L_{j} \quad$ Jump length (L)

$L_{s}$ Distance from gate to screen (L)

$P_{l} \quad$ Hydrostatic pressure at the beginning of the hydraulic jump

$P_{4}$ Hydrostatic pressure at the end of the hydraulic jump

Ps Hydrostatic pressure below one side of contraction

$\mathrm{p}_{\mathrm{c} 1}$ Hydrostatic pressure before screen

$\mathrm{p}_{\mathrm{c} 2}$ Hydrostatic pressure after screen

$\mathrm{p}_{\text {cnet }}$ Net pressure applied on screen

$n$ Number of holes (-)

$S$ Submergence ratio $\left(\mathrm{y}_{3} / \mathrm{y}_{1}\right)(-)$

$v_{1}$ Velocity at section $1\left(\mathrm{LT}^{-1}\right)$

$v_{4}$ Velocity at $\mathrm{y}_{4}\left(\mathrm{LT}^{-1}\right)$
$\mathrm{X}$ distance from the gate at any water depth

$\mathrm{Y}$ relative depth of jump

$\mathrm{y}$ depth of water at distance $\mathrm{X}$

$y_{1}$ Initial water depth (L)

$y_{2}$ Sequent water depth (L)

$y_{3}$ Back flow depth (L)

$\mathrm{y}_{4}$ Tail water depth (L)

$\mathrm{y}_{\mathrm{s}}$ Depth at the side expansions of the basin (L)

$\rho$ Density of water (ML-3)

\section{References}

[1] A. Abbaspour, T. Taghavianpour, H. Arvanaghi, "Experimental study of the hydraulic jump on reverse bed with porous screens", Applied Water Science, 9(7): 155,2019 .

[2] G.M. Abdel-Aal, "Study of free flow conditions for sill under gate", Unpublished M. Sc., Faculty of engineering, Ain shams university, Egypt1990.

[3] F.S.F. Abdelhaleem, "Hydraulics of submerged radial gates with a sill", ISH Journal of Hydraulic Engineering, 23(2): 177-186,2017.

[4] G. Balkiş, 2004. Experimental investigation of energy dissipation through inclined screens, Doctoral dissertation, Middle East Technical Univercity, Ankara, Turkey.

[5] M.S. Bejestan, K. Neisi, "A new roughened bed hydraulic jump stilling basin", Asian journal of applied sciences, 2(5): 436-445,2009.

[6] Z. Bozkus, P. Çakir, A.M. Ger, "Energy dissipation by vertically placed screens", Canadian Journal of Civil Engineering, 34(4): 557-564,2007.

[7] Z. Bozkuş, E. Güngör, M. Ger, "Energy dissipation by triangular screens", Journal, (Issue): 2006.

[8] R. Bremen, W. Hager, "The Submerged Hydraulic Jump In An Abrupt Lateral Expansion: CD Smith, Vol. 27, No. 2, 1989, pp. 257-266", 1990.

[9] R. Bremen, W.H. Hager, "Expanding stilling basin", Proceedings of the Institution of Civil Engineers - Water, Maritime and Energy, 106(3): 215-228,1994.

[10] R. Bremen, W.H. Hager, "T-jump in abruptly expanding channel", Journal of Hydraulic Research, 31(1): 61-78,1993.

[11] V.I. Bukreev, "Undular Jump in Open- Channel Flow Over a Sill", Journal of Applied Mechanics and Technical Physics, 42(4): 596-602,2001.

[12] P. Cakir, 2003. Experimental investigation of energy dissipation through screens, Citeseer.

[13] R. Daneshfaraz, S. Sadeghfam, A. Tahni, "Experimental investigation of screen as energy dissipators in the movablebed channel", Iranian Journal of Science and Technology, Transactions of Civil Engineering: 1-10,2019.

[14] A. Eloubaidy, J. Al-Baidhani, A. Ghazali, "Dissipation of hydraulic energy by curved baffle blocks", Pertanika Journal Science Technology, 7(1): 69-77,1999.

[15] M. Fathi-Moghadam, S. Haghighipour, B. Lashkar-Ara, P. Aghtouman, "Reduction of stilling basin length with tall end sill", Journal of Hydrodynamics, Ser. B, 23(4): 498$502,2011$.

[16] M. Fathi-Moghadam, S. Kiani, P. Asiaban, R. Behrozi-Rad, "Modeling of perforated sill-controlled hydraulic jump", International Journal of Civil Engineering, 15(4): 689695,2017.

[17] P. France, "Analysis of the hydraulic jump within a diverging rectangular channel", Proceedings of the Institution of Civil Engineers, 71(2): 369-378,1981. 
[18] W.H. Hager, "Hydraulic jump in non-prismatic rectangular channels", Journal of Hydraulic Research, 23(1): 2135,1985 .

[19] W.H. Hager, D. Li, "Sill-controlled energy dissipator", Journal of Hydraulic Research, 30(2): 165-181,1992.

[20] M.I. Mahmoud, S.S. Ahmed, A. Al-Fahal, "Effect of different shapes of holes on energy dissipation through perpendicular screen", Journal of Environmental Studies, 12: 29-37,2013.

[21] Y.A. Mohamed, Y.K. Saleh, A.M. Ali, "Studying the effect of different configurations and positions of sill over stilling basin on flow characteristics behind radial gate,(case study: nagaa hammadi regulator", 2015.

[22] A.M. Negm, G. Abdel-Aal, M. Elfiky, Y. Mohmed, "Hydraulic characteristics of submerged flow in nonprismatic stilling basins", Journal, (Issue): 2002.

[23] A.M. Negm, G.M. Abdel-Aal, A.A. Habib, T.M. Owais, "Effect of end sill in radial basin on characteristics of free hydraulic jumps", Journal, 1(Issue): 12,2003.

[24] N. Rajaratnam, K. Hurtig, "Screen-type energy dissipator for hydraulic structures", Journal of Hydraulic Engineering, 126(4): 310-312,2000.

[25] S. Sadeghfam, A.A. Akhtari, R. Daneshfaraz, G. Tayfur, "Experimental investigation of screens as energy dissipaters in submerged hydraulic jump", Turkish Journal of Engineering and Environmental Sciences, 38(2): 126$138,2015$.

[26] F. Tajabadi, E. Jabbari, H. Sarkardeh, "Effect of the end sill angle on the hydrodynamic parameters of a stilling basin", The European Physical Journal Plus, 133(1): 10,2018.

[27] H.K. Zare, J.C. Doering, "Energy dissipation and flow characteristics of baffles and sills on stepped spillways", Journal of Hydraulic Research, 50(2): 192-199,2012. 